\title{
Saddle block spinal anesthesia and its effect on hemodynamic status and analgesia
}

\author{
Neeta S. ${ }^{1}$, Sunil B. V., ${ }^{2,}$, Sonal Bhat ${ }^{3}$, Shaila Kamath ${ }^{4}$, Madhusudan U. ${ }^{5}$ \\ ${ }^{1}$ Assistant Professor, ${ }^{2,3}$ Associate Professor, ${ }^{4,5}$ Professor, Dept. of Anaesthesia, Kasturba Medical College, Manipal University of \\ Higher Education, Mangalore, Karnataka, India
}

*Corresponding Author:

Email: drsunilbv@gmail.com

Received: $21^{\text {st }}$ June, 2017

Accepted: $04^{\text {th }}$ October, 2017

\begin{abstract}
Introduction: The sitting position is often used for patients undergoing spinal anesthesia especially when lower lumbar and sacral levels of sensory anesthesia are required. An advantage of this position is that the complications associated with it can be reduced. The present study assess the relation between saddle block anesthesia and the duration spent in sitting posture.

Materials and Methods: Sixty ASA I and II patients were included in this study. In this randomized controlled study, patients planned to undergo perineal procedures were selected. Spinal anesthesia was given with $2.2 \mathrm{ml}$ of $0.5 \%$ hyperbaric bupivacaine and the patients were made to sit for one, six, twelve and twenty minutes before making them supine for the procedure. The data were analyzed using students ' $t$ ' test and .Chi - Square test .

Results: Better hemodynamic stability was achieved by increasing the duration of sitting posture after spinal anesthesia. Also duration of motor /sensory blockade was decreased by increasing the duration of sitting position.

Conclusion: The study shows that the duration of sitting position is inversely related to the duration and extent of sensory and motor blockade. Also better hemodynamic stability can be achieved with saddle block anesthesia.
\end{abstract}

Keywords: Spinal anesthesia, Sympathetic blockade, Hyperbaric bupivacaine, Cerebrospinal fluid.

\section{Introduction}

Spinal anesthesia is useful in procedures involving lower extrimity. Advantages of subarachnoid block include patient remaining fully awake, maintenance of normal physiology, lesser incidence of deep vein thrombosis and aspiration syndrome. ${ }^{1} \quad$ The disadvantages include hypotension, bradycardia, urinary retention and unduly prolonged motor paralysis. $^{2}$ The position of the patient during injection and the position for the next 20 minutes determines the distribution of hyperbaric solution like hyperbaric $0.5 \%$ bupivacaine. After that, distribution should no longer be significantly affected by position. The sitting position is often used for patients undergoing spinal anesthesia especially when lower lumbar and sacral levels of sensory anesthesia are required for surgical procedure such as perineal and urological procedures. The sitting position during and after injection; restricts the distribution of drug to lower lumbar and sacral roots. ${ }^{3}$ However the relation between the nerve blockade produced and the duration spent in sitting posture still needs explanation.

In the present study we are studying the relation between the nerve blockade produced and the time spent in sitting posture.

\section{Aim}

1. To examine the duration of motor and extent of sensory blockade following spinal block with $0.5 \%$ bupivacaine and its relation with the different time durations spent in sitting position.
2. To assess the hemodynamic effects on time duration spent in sitting posture following spinal block.

\section{Materials and Methods}

Following hospital ethics committee clearance and written informed consent, 60 ASA I and II patients were included in the randomized controlled study. Patients posted for anal and peri anal surgeries under spinal anesthesia were included for the study.

A. Inclusion criteria

1. American society of Anaesthesiology I and II

2. Age group 35-60 years.

B. Exclusion criteria

1. Medically not fit for spinal anesthesia

2. Patient refusal

3. Deformities of vertebral column

4. Neurological diseases

5. Coagulaopathy

6. Valvular heart disease

The prospective randomized study included 60 patients, divided into four groups based on the period of sitting.

Group A: Patients were maintained in sitting position for one minutes.

Group B: Patients were maintained in sitting position for six minutes.

Group C: Patients were maintained in sitting position for twelve minutes.

Group D: Patients were maintained in sitting position for twenty minutes. 
Sample size was predetermined using a power analysis: $\alpha=0.05$ and $\beta=0.2$ (SD: 0.84 , mean difference: 1.68 , normal two-sided test). According to randomization list, 60 cases were divided into 4 groups consisted of 15 case each.

After preanaesthetic evaluation, nil per mouth orders were given. Adequate preloading before spinal anesthesia was ensured Patients were placed in sitting position. After ensuring strict asepsis, spinal anesthesia was given with 25 gauge Quincke Babcock needle. Totel Volume of $2.2 \mathrm{ml}$ of hyperbaric bupivacaine $(0.5 \%)$ was used for the study. Following the procedure patients maintained in sitting position for 1 min, 6 min, 12 min and 20 minutes and were made to lie down. Each group had 15 patients.

Pinprick method along the anterior axillary line was used to assess sensory blockade.

Assessments were made every 5 minutes during the first 30 minutes after spinal anesthesia and then at $45 \mathrm{~min}$. Analgesia was defined as inability to detect sharp pin prick.

Motor blockade was recorded by asking the patients to lift the extended leg every 5 minutes till 30 minutes after making them supine and then at 45 minutes.

Bromage Scoring was used to assess motor block.

Heart rate, systolic, diastolic and mean arterial pressure were monitored and recorded every two minutes for ten minutes and every five minutes until thirty minutes and then at forty five and sixty minutes. Hypotension and bradycardia were treated with ephedrine and atropine respectively

\section{Statistical Analysis}

Statistical analysis was done using Chi - Square test and students ' $t$ ' test [SPSS version 16.0 was used for data analysis].

\section{Results}

There was no statistically significant variation in age and gender distribution.

There was no statistically significant variation between the groups in heart rate. Statistically significant variations in systolic blood pressure was seen starting from fifteen minutes. hypotension was significant in group A after spinal administration of $0.5 \%$ bupivacaine which was stabilised with fluids and vasopressor like ephedrine. (Table 1). diastolic blood pressure also showed variation from 4 minutes onwards following spinal anesthesia, Which is statistically significant. (Table 2).

Maximal level of sensory blockade acheived (Table 3). For group A the maximal level of sensory blockade achieved was T6 and for group B,the level was T8. While a level of T10 was achieved by group C and a level of T12 was achieved by group D.

Motor blockade achieved by each group (Graph 1 ). complete blockade of knee joint was observed in all patients of group A. in group B, $80 \%$ showed complete blockade while $20 \%$ of the patients had partial blockade. $60 \%$ of the patients in group $\mathrm{C}$ had there knee joint completely blocked while $20 \%$ had partial blockade and $20 \%$ had no blockade.while in group D $40 \%$ showed complete blockade, $20 \%$ of the patients showed no motor blockade, and $40 \%$ showed partial blockade of the knee joint. 
Table 1: Systolic Blood Pressure

SBP

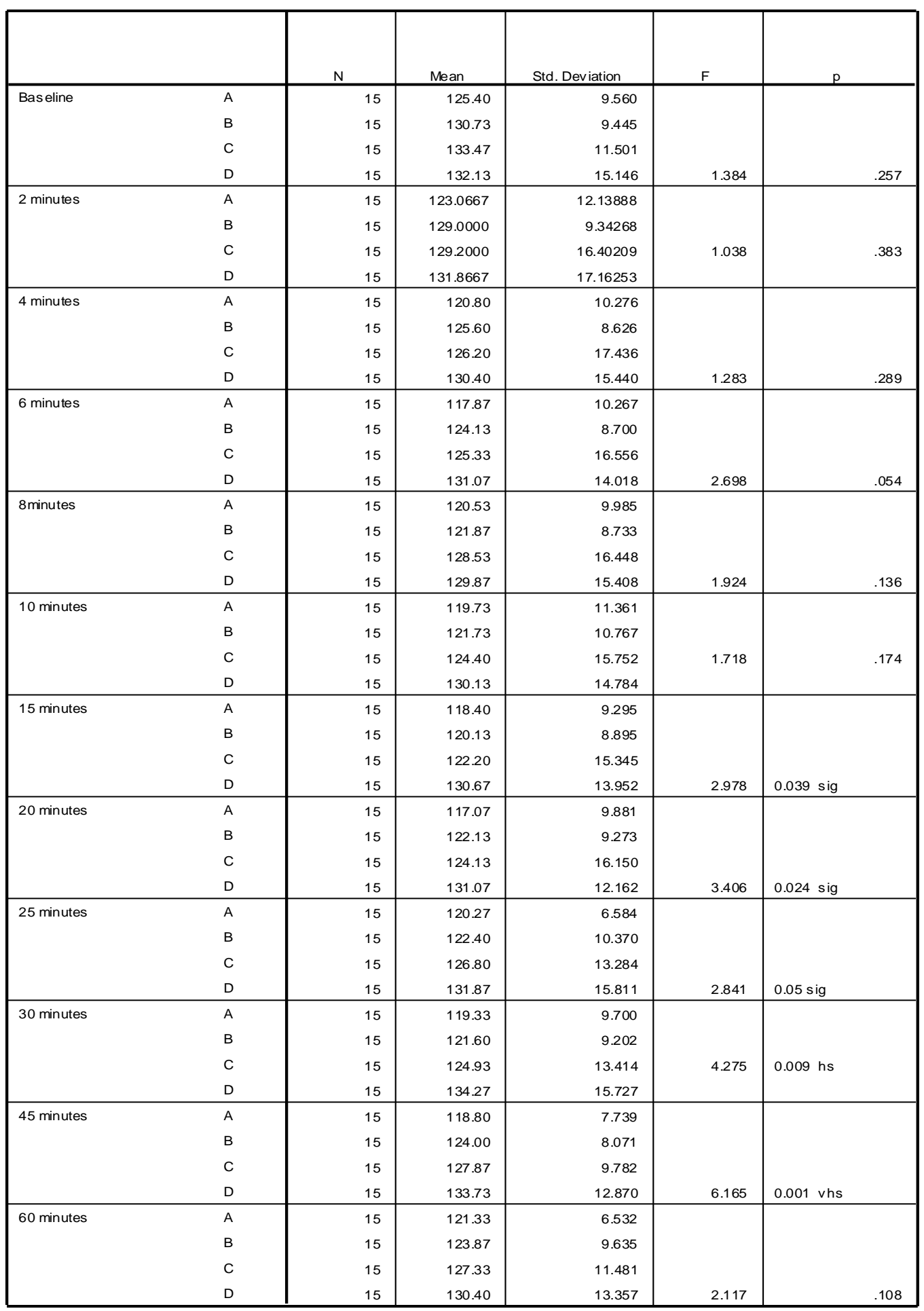


Table 2: Diastolic blood pressure

\begin{tabular}{|c|c|c|c|c|c|c|}
\hline & & $\mathrm{N}$ & Mean & Std. Deviation & $\mathrm{F}$ & $\mathrm{p}$ \\
\hline \multirow[t]{4}{*}{ Bas eline } & A & 15 & 79.7333 & 5.89754 & \multirow[b]{4}{*}{3.503} & \multirow[b]{4}{*}{$0.021 \mathrm{sig}$} \\
\hline & B & 15 & 82.2667 & 4.52717 & & \\
\hline & C & 15 & 85.2000 & 8.61228 & & \\
\hline & $\mathrm{D}$ & 15 & 87.8000 & 8.99365 & & \\
\hline \multirow[t]{4}{*}{2 minutes } & A & 15 & 76.8000 & 7.73859 & \multirow[b]{4}{*}{2.517} & \multirow[b]{4}{*}{.067} \\
\hline & B & 15 & 83.0667 & 9.82320 & & \\
\hline & C & 15 & 85.3333 & 11.72705 & & \\
\hline & $\mathrm{D}$ & 15 & 85.2667 & 9.53540 & & \\
\hline \multirow[t]{4}{*}{4 minutes } & A & 15 & 75.8667 & 5.82932 & \multirow[b]{4}{*}{4.121} & \multirow[b]{4}{*}{$0.01 \mathrm{hs}$} \\
\hline & B & 15 & 80.4000 & 7.17934 & & \\
\hline & C & 15 & 83.2667 & 9.09055 & & \\
\hline & $\mathrm{D}$ & 15 & 85.6000 & 9.35643 & & \\
\hline \multirow[t]{4}{*}{6 minutes } & A & 15 & 74.5333 & 7.22957 & \multirow[b]{4}{*}{3.696} & \multirow[b]{4}{*}{$0.017 \mathrm{sig}$} \\
\hline & B & 15 & 78.8000 & 9.22109 & & \\
\hline & $\mathrm{C}$ & 15 & 80.1333 & 8.36546 & & \\
\hline & $\mathrm{D}$ & 15 & 85.5333 & 11.25590 & & \\
\hline \multirow[t]{4}{*}{8 minutes } & A & 15 & 73.7333 & 5.11952 & \multirow[b]{4}{*}{3.512} & \multirow[b]{4}{*}{$0.021 \mathrm{sig}$} \\
\hline & B & 15 & 77.1333 & 8.70851 & & \\
\hline & $\mathrm{C}$ & 15 & 80.8000 & 9.96566 & & \\
\hline & $\mathrm{D}$ & 15 & 84.6000 & 13.16814 & & \\
\hline \multirow[t]{4}{*}{10 minutes } & A & 15 & 73.7333 & 5.22995 & \multirow[b]{4}{*}{3.011} & \multirow[b]{4}{*}{0.038 sig } \\
\hline & B & 15 & 76.2667 & 9.61744 & & \\
\hline & C & 15 & 81.7333 & 9.79407 & & \\
\hline & $\mathrm{D}$ & 15 & 82.2000 & 11.34019 & & \\
\hline \multirow[t]{4}{*}{15 minutes } & A & 15 & 73.1333 & 6.66405 & \multirow[b]{4}{*}{3.504} & \multirow[b]{4}{*}{$0.021 \mathrm{sig}$} \\
\hline & B & 15 & 76.2667 & 9.28491 & & \\
\hline & $\mathrm{C}$ & 15 & 80.4667 & 10.57535 & & \\
\hline & $\mathrm{D}$ & 15 & 82.8667 & 8.88712 & & \\
\hline 20 minutes & A & 15 & 71.9333 & 5.50930 & & \\
\hline & B & 15 & 78.1333 & 7.76316 & & \\
\hline & C & 15 & 83.2000 & 8.74398 & & \\
\hline & $\mathrm{D}$ & 15 & 81.4667 & 6.61024 & 7.023 & $.001 \mathrm{vhs}$ \\
\hline 25 minutes & A & 15 & 72.8000 & 5.49285 & & \\
\hline & B & 15 & 75.7333 & 8.48079 & & \\
\hline & $\mathrm{C}$ & 15 & 83.3333 & 9.06064 & & \\
\hline & $\mathrm{D}$ & 15 & 80.7333 & 8.11055 & 5.441 & $0.002 \mathrm{hs}$ \\
\hline 30 minutes & A & 15 & 72.1333 & 5.20805 & & \\
\hline & B & 15 & 75.6000 & 6.76968 & & \\
\hline & $\mathrm{C}$ & 15 & 84.1333 & 8.43349 & & \\
\hline & $\mathrm{D}$ & 15 & 82.8000 & 10.08677 & 8.059 & $.001 \mathrm{vhs}$ \\
\hline 45 minutes & A & 15 & 74.1333 & 4.74893 & & \\
\hline & B & 15 & 75.6000 & 5.94979 & & \\
\hline & C & 15 & 83.9333 & 7.07578 & & \\
\hline & D & 15 & 80.1333 & 11.25590 & 5.083 & $0.003 \mathrm{hs}$ \\
\hline 60 minutes & A & 15 & 73.2000 & 5.28069 & & \\
\hline & B & 15 & 79.0667 & 9.46774 & & \\
\hline & C & 15 & 84.8000 & 6.62463 & & \\
\hline & D & 15 & 82.1333 & 8.15796 & 6.540 & $.001 \mathrm{vhs}$ \\
\hline
\end{tabular}

Table 3: Level of sensory blockade

\begin{tabular}{|c|c|c|c|c|c|c|}
\hline Group & T6 & T8 & T10 & T12 & L1 & S4 \\
\hline A & 2 & 10 & 2 & 1 & 0 & 0 \\
\hline B & 0 & 5 & 6 & 3 & 1 & 0 \\
\hline C & 0 & 0 & 5 & 7 & 2 & 1 \\
\hline D & 0 & 0 & 0 & 4 & 5 & 6 \\
\hline
\end{tabular}




\section{Graph 1: Motor Blockade}

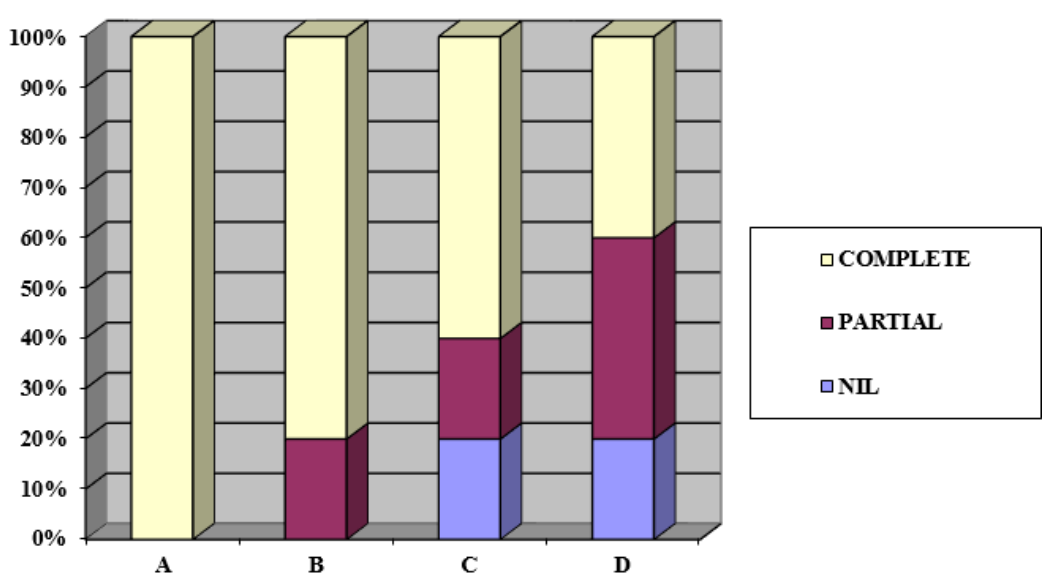

\section{Discussion}

Spinal anesthesia has been widely used safely and effectively by many anesthesiologists. The lumbar lordosis has effect on the spread of hyperbaric local anesthetic. Hyperbaric local anesthetic administered at interspaces lower than L3-L4 has a tendency to pool in sacral area. ${ }^{4}$

The above study was carried out in 60 ASA I-II patients. Based on the time spent in sitting position after giving intrathecal block, they were divided into four groups. The results have shown that prolonging the time of sitting posture after spinal anesthesia has considerable influence on the localization of the blockade. In all the four groups, the demographic variables and heart rate didn't show any significant difference.

In a randomized controlled study, sixty patients were posted for lower abdominal surgery. They were divided equally into 2 groups. In Group I, patients were kept in sitting position for a period of 30 seconds following injecting $1.5 \mathrm{ml}$ of $0.5 \%$ hyperbaric bupivacaine and in Group II patients were made supine immediately after intrathecal injection. Postoperatively, the pain score was recorded. The study has shown that the sitting position helps to prevent high spinal and gives better hemodynamic stability. These findings were similar to our study. ${ }^{5}$

In another study, $(0.75 \%) 10 \mathrm{mg}$ of hyperbaric bupivacaine was injected intrathecally in elderly patients. Patients were made to lie in supine position 5, 10 and 15 minutes after spinal anesthesia. It was found that the duration of time spent in sitting position has very little and insignificant influence in final analgesia level and haemodynamic changes in elderly patients undergoing minor urological procedures. These findings were contradicting our findings. ${ }^{6}$

In a study comparing fifty seven patients scheduled for transurethral surgery, $6.5 \mathrm{mg}$ of hyperbaric bupivacaine was injected to the subarachnoid space. One group was made to lie supine immediately and other group remained in sitting posture for two minutes and then were made supine. The hemodynamic stability was more and the level of sensory blockade achieved was lesser for the group which was made to sit for two minutes. It was concluded that performing a spinal anesthesia in sitting position was technically easier and induced less hypotension. These findings were similar to our findings.

In another study done on two hundred and sixty patients who were scheduled to undergo minor anorectal procedures, spinal anesthesia was performed with $1 \mathrm{ml}$ of $0.5 \%$ hyperbaric bupivacaine. After 1 minute of sitting posture patients were placed in jack knife position. There was no adverse hemodynamic events during the procedure. These observations were similar to our findings. ${ }^{8}$

Vallath etal did a study on 150 patients, who were made to sit for extended period of time after spinal anesthesia. They also found that hemodynamic stability can be improved by making the patients sit for a longer duration of time. The results of this study were comparable with the present study. ${ }^{9}$

Hence it was observed that as the time duration spent in sitting posture following spinal anesthesia is more, the hyperbaric bupivacaine gets fixed at the dependent position providing lesser and localized sensory, motor blockade and better stability in hemodynamic parameters. The theory behind this action could be the fixation of the drug due to gravity so that positional changes afterwards will not have much effect on the spead of the drug.

\section{Conclusion}

The present study conclude that the time maintained in sitting posture following spinal anesthesia has considerable effect on the localization of the drug along with lesser sensory and motor blockade and ensures safe hemodynamics.

\section{References}

1. Nganga N. Spinal anaesthesia: advantages and disadvantages. East Afr Med J. 2010 Jun;87(6):225-6. 
2. Hyderally H. Complications of spinal anesthesia. Mt Sinai J Med. 2002 Jan-Mar;69(1-2):55-57.

3. Susmita B, Subrata B, Mandeep K, Suchismita M. Regional anesthesia in transurethral resection of prostate (TURP) surgery: A comparative study between saddle block and subarachnoid block. Saudi J Anaesth. 2015 JulSep;9(3):268-71.

4. Hocking $\mathrm{G}$, Wildsmith $\mathrm{W}$. Intrathecal drug spread.Br J Anaesth 2004 93(4):568-78.

5. Nandkishore A, Sujata R. Spinal Anaesthesia in Sitting Position for 30 Seconds Vs Conventional Spinal Anaesthesia: Which is Better. People's Journal of Scientific Research January 2017;(10)1-4.

6. Muzamil H, Nasreen I. Comparison of the Effect of Duration Spent in Sitting Position on the Level of Block, Heart Rate and Blood Pressure with Hyperbaric
Bupivacaine $(0.75 \%)$ During Spinal Anaesthesia. Proceeding S.Z.P.G.M.I.2012 Vol:26(1):25-32.

7. Young K, Myeong J, Sub K, Won S, Kyu C. Effect of position changes after spinal anesthesia with low-dose bupivacaine in elderly patients: sensory block characteristics and hemodynamic changes. Korean J Anesthesiol 2013;64:234-9.

8. Soo Y, Jong C, Sang H. It Useful and Safe to Maintain the Sitting Position During Only One Minute before Position Change to the Jack-knife Position .Korean J Pain 2010; 23:190-7.

9. Vallath etal .Effectiveness of duration spent in sitting posture on the spread of $3 \mathrm{ml}$ of $0.5 \%$ hyperbaric bupivacaine in subarachnoid block.J Anesth Pharmacol 2005;21;155-7.10. 